Isabel de Abreu Farias

\title{
Mensuração do Desempenho de Exportação: As Perspectivas dos Gestores e dos Acadêmicos
}

Dissertação apresentada ao Programa de Pósgraduação em Administração de Empresas da PUCRio como requisito parcial para obtenção do grau de Mestre em Administração de Empresas.

Orientador: Prof. Jorge Manoel Teixeira Carneiro 


\section{Pontifícia Universidade Catálica $_{\text {a }}$

Isabel de Abreu Farias

\section{Mensuração do Desempenho de Exportação: As Perspectivas dos Gestores e dos Acadêmicos}

Dissertação apresentada como requisito parcial para obtenção do grau de Mestre pelo Programa de PósGraduação em Administração de Empresas da PUCRio. Aprovada pela Comissão Examinadora abaixo assinada.

Prof. Jorge Manoel Teixeira Carneiro

Orientador

Departamento de Administração da PUC-Rio

Prof. Jorge Ferreira da Silva

Departamento de Administração da PUC-Rio

Profa. Angela Maria Cavalcanti da Rocha Instituto Coppead de Administração - UFRJ

Prof. Nizar Messari

Vice-Decano de Pós-Graduação do CCS

Rio de Janeiro, 01 de setembro de 2009. 
Todos os direitos reservados. É proibida a reprodução total ou parcial do trabalho sem autorização da universidade, da autora e do orientador.

\section{Isabel de Abreu Farias}

Graduada em Administração de Empresas pela Universidade Federal do Rio de Janeiro (UFRJ) em 2007, com curso de Formação em Administração Internacional pelo Instituto Coppead de Administração da UFRJ. Trabalhou na área de pesquisa em administração internacional no Instituto Coppead de Administração da UFRJ. Seus interesses de pesquisa estão relacionados à estratégia e internacionalização de empresas.

Ficha Catalográfica

Farias, Isabel de Abreu

Mensuração do desempenho de exportação: as perspectivas dos gestores e dos acadêmicos / Isabel de Abreu Farias; orientador: Jorge Manoel Teixeira Carneiro. - 2009.

$158 \mathrm{f}$; $30 \mathrm{~cm}$

Dissertação (Mestrado em Administração)Pontifícia Universidade Católica do Rio de Janeiro, Rio de Janeiro, 2009.

Inclui bibliografia

1. Administração - Teses. 2. Desempenho de exportação. 3. Exportadores brasileiros. 4. Mensuração do desempenho. 5. Negócios internacionais. I. Carneiro, Jorge Manoel Teixeira. II. Pontifícia Universidade Católica do Rio de Janeiro. Departamento de Administração. III. Título. 
Dedico este trabalho a Deus, aos meus pais, Maria da Glória e Antonio, e a minha irmã,

Rosane. 


\section{Agradecimentos}

Viver é a arte do aprendizado. A cada dia, renovamos-nos, reciclamo-nos, renascemos a partir da constante interação com o outro que nos constrói e nos destrói. Neste momento, quero expressar formalmente a todos aqueles que participaram e que virão a participar na construção e reconstrução de mim o meu eterno agradecimento, pois enumerá-los seria impossível.

Desejo agradecer em especial ao Professor Jorge Carneiro, meu orientador, por todo o apoio, orientação acadêmica e empenho no desenvolvimento desta dissertação, sem ele este trabalho não teria sido possível.

À professora Angela da Rocha por disponibilizar verbas do PRONEX / FAPERJ / CNPq para despesas da pesquisa de campo e por seus conselhos acadêmicos para o desenvolvimento da linha de pesquisa em Desempenho Organizacional em que esta dissertação se insere.

À Flávia Schmidt, aluna do doutorado, pela ajuda na pesquisa de campo, assim como pelos conselhos e pelos agradáveis momentos de descontração na sala dos mestrandos e doutorandos.

Agradeço ao professor José Roberto (in memorian) e aos executivos e empresas que me auxiliaram no pré-teste do roteiro de entrevista e aos que disponibilizaram não apenas o precioso tempo (time is money) para me receber, mas também o valioso conhecimento prático que tinham da área de exportação.

Agradeço ao IAG - PUC Rio, aos professores desta instituição pela oportunidade de aprendizado que me proporcionaram, aos funcionários, em especial a Teresa Campos e ao Fábio Etienne, e à CAPES pela bolsa de estudos, pois sem ela este sonho não teria saído do abstrato para o real. 
A Bárbara Martins, Monique Sampaio, Lavilha Sá e Luciana Velloso por compartilharem os picos e vales de todo este processo de amor e ódio à dissertação e a todos os outros amigos e amigas que fiz no mestrado e durante o mestrado.

Agradeço também aos amigos, amigas e familiares que souberam, tantas vezes, compreender pacientemente as minhas repetidas respostas "hoje não posso, estou estudando" ou "hoje não posso, estou trabalhando na dissertação". Obrigada por compreenderem a minha ausência.

E, por fim, agradeço aqueles que foram o começo de tudo: meus pais e minha irmã, Rosane, que sempre me incentivaram a estudar e acreditaram que eu poderia ir além. A vocês deixo, não somente o meu muito obrigada, mas também o meu amor por toda eternidade. Sem vocês eu nada seria! 


\section{Resumo}

Farias, Isabel de Abreu; Carneiro, Jorge Manoel Teixeira. Mensuração do Desempenho de Exportação: As Perspectivas dos Gestores e dos Acadêmicos. Rio de Janeiro, 2009. 158p. Dissertação de Mestrado Departamento de Administração, Pontifícia Universidade Católica do Rio de Janeiro.

O presente estudo tem por objetivo estudar a temática de desempenho de exportação sobre a ótica teórica e prática. Para isto, foram revisados os principais modelos teóricos utilizados para avaliar o desempenho de exportação e buscou-se confrontar as variáveis utilizadas nestes estudos com as variáveis utilizadas pelos gestores de exportação dentro do ambiente organizacional. A metodologia utilizada foi: (i) pesquisa bibliográfica a trabalhos conceituais sobre o construto de desempenho de exportação, a revisões de literatura e a estudos empíricos; (ii) entrevistas semi-estruturadas com 15 gestores de empresas exportadoras nacionais para identificar as principais dimensões e indicadores considerados na medição do desempenho de exportação. Como resultados principais desta análise, percebeu-se que, em geral, os gestores entrevistados: utilizam um horizonte de curto prazo para as análises dos resultados das atividades de exportação; não possuem informações sobre os concorrentes no mercado externo; utilizam principalmente variáveis de medidas econômico-financeiras e de mercado de orientação temporal absoluta; e, utilizam os mesmos indicadores tanto para definir atividades exportadoras de sucesso quanto de fracasso.

\section{Palavras-chave}

Desempenho de exportação; exportadores brasileiros; mensuração do desempenho; negócios internacionais. 


\section{Abstract}

Farias, Isabel de Abreu; Carneiro, Jorge Manoel Teixeira (Advisor). Measurement of Export Performance: The Perspectives of Managers and Academics Rio de Janeiro, 2009. 158p. MSc. Dissertation Departamento de Administração, Pontifícia Universidade Católica do Rio de Janeiro.

The objective of this study is to examine the issue of export performance from a theoretical and a practical perspective. Theoretical models used to assess the export performance were reviewed and the variables used in these studies were compared with the variables used by export managers within the organizational environment. The methodology was: (i) literature review of conceptual works about the construct of export performance, reviews of literature and empirical studies, (ii) semi-structured interviews with 15 managers of national exporting companies to identify the key dimensions and indicators considered in measuring the performance of exports. As main results of this analysis, it is understood that, in general, the managers interviewed: use a short-term horizon to analyze the results of exports activities, do not have information about competitors in foreign markets, mainly using economic/financial and market variables measures with absolute time orientation, and use the same indicators to define success or failure of export activities.

\section{Keywords}

Export performance; brazilian exporters; performance measures; international business. 


\section{Sumário}

1. Introdução 15

1.1. Pergunta de Pesquisa e Objetivos do Estudo 18

1.2. Contribuições do Estudo 19

1.3. Delimitação do Escopo do Estudo 20

1.4. Organização da Presente Pesquisa 20

2. Referencial Teórico 21

2.1. O Construto Desempenho 21

2.1.1. Aspectos Conceituais do Desempenho Organizacional 21

2.1.2. Particularidades do Desempenho de Exportação versus

2.1.3. Revisão Crítica de Modelos Conceituais de Desempenho de Exportação 26

2.1.4. Esquema Analítico Genérico do Desempenho de
Exportação

2.2. Operacionalização do Desempenho de Exportação 32

2.2.1. Revisão De Modelos de Desempenho de Exportação em Estudos Empíricos 32

2.2.2. Indicadores de Desempenho de Exportação 38

2.3. Os Conceitos de Sucesso e de Fracasso 43

2.3.1. A Perspectiva do Sucesso e do Fracasso na Literatura
sobre Novos Produtos

2.3.2. A Perspectiva do Sucesso e do Fracasso na Literatura sobre Desempenho de Exportação 48

3. Dados e Métodos 50

3.1. Pesquisa Qualitativa 51

3.2. Seleção dos Casos de Estudo e dos Respondentes 53

3.3. Procedimentos de Coleta de Dados 55

3.4. Procedimentos de Tratamento e de Análise dos Dados $\quad 59$

3.5. Limitações do Método 63

4. Perfil das Empresas 65

5. Descrição das Entrevistas 69

5.1. Entrevista $1 \quad 69$

5.2. Entrevista $2 \quad 72$

5.3. Entrevista $3 \quad 73$

5.4. Entrevista $4 \quad 75$

5.5. Entrevista 5

5.6. Entrevista $6 \quad 79$

5.7. Entrevista $7 \quad 80$

5.8. Entrevista 8

5.9. Entrevista 9

5.10. Entrevista 10

5.11. Entrevista $11 \quad 87$

5.12. Entrevista 12 
5.13. Entrevista $13 \quad 90$

5.14. Entrevista 14

5.15. Entrevista 15

5.16. Indicadores Citados por Entrevista 97

6. Discussão dos Resultados 103

6.1. Formas de Exportação Utilizadas e Atitude Exportadora 103

6.2. Informações sobre Resultados Passados de Exportação 106

$\begin{array}{ll}\text { 6.3. Informações sobre a Concorrência e Comparação entre } & 110 \\ \text { Resultados de Exportação } & 110\end{array}$

6.4. Diferenças e Semelhanças entre as Variáveis de

Desempenho de Exportação Utilizadas pelos Gestores em

Comparação com as Sugeridas pelos Acadêmicos

118

6.5. Critérios de Desempenho Utilizados para se Medir os

Resultados de uma Operação de Exportação de Sucesso Versus

de Fracasso

125

6.6. Proposta de Mensuração de Desempenho para os

Acadêmicos e Gestores

129

7. Considerações Finais

131

7.1. Síntese do Estudo 131

7.2. Conclusões do Estudo 133

7.3. Recomendações para Acadêmicos e para Executivos 138

7.4. Discussão Sobre os Conceitos de Sucesso e Fracasso 140

7.5. Limitações do Estudo 141

7.6. Sugestões para Pesquisas Futuras 142

$\begin{array}{ll}\text { 8. Referências Bibliográficas } & 143\end{array}$

Apêndices 150

Apêndice 1. Roteiro para Entrevistas 150

Apêndice 2. Informações sobre o Perfil do Entrevistado e da
Empresa 


\section{Tabelas}

Tabela 1 - Esquema analítico genérico para caracterização do desempenho de exportação

Tabela 2 - Relação de Indicadores de Desempenho de

Exportação Empregados em Pesquisas na Área de Negócios

Internacionais no Período de 1985-2005

Tabela 3 - Medidas de Sucesso no Desenvolvimento de Novos

Produtos

Tabela 4 - Perfil das Empresas Entrevistadas e dos

Entrevistados

66

Tabela 5 - Indicadores de Desempenho de Exportação Citados por Entrevista

Tabela 6 - Formas de Exportação Utilizadas e Atitude

Exportadora Citados por Entrevista

105

Tabela 7 - Informações Sobre Resultados Passados de

Exportação por Entrevista

109

Tabela 8 - Informações Sobre a Concorrência e Comparação

entre Resultados de Exportação

Tabela 9 - Relação dos Indicadores de Desempenho de

Exportação Relatados pelos Gestores

Tabela 10 - Indicadores de Desempenho Relatados nos Casos de Sucesso e de Fracasso

Tabela 11 - Principais Contrastes Encontrados entre as

Perspectivas dos Acadêmicos e dos Gestores

133

Tabela 12 - Principais Semelhanças Encontradas entre as

Perspectivas dos Acadêmicos e dos Gestores 


\section{Quadros}

Quadro 1 - Crescimento do Volume das Exportações e do PIB Mundial Real, 2000-2007

Quadro 2 - Evolução das Exportações Brasileiras entre 2000 e 2008 


\title{
Abreviaturas e Siglas
}

\author{
APEV - Annual Performance of an Export Venture \\ BSC - Balanced Scorecard \\ DEPLA - Departamento de Desenvolvimento e Planejamento De Comércio \\ Exterior \\ EXPERF - Export Performance \\ PADR - Prospector, Analyzer, Defender e Reactor \\ PIB - Produto Interno Bruto \\ STEP - Short-Term Export Performance \\ WTO - World Trade Organization
}


"Sabedoria é a capacidade de prever as consequências, a longo prazo, de ações atuais, a disposição de sacrificar ganhos a curto prazo em favor de benefícios a longo prazo e a habilidade de controlar o que é controlável e de não se afligir com o que não o é. A essência da sabedoria, portanto, é a preocupação com o futuro. Não é, porém, a preocupação com o futuro que o adivinho tem; ele só tenta prevê-lo. O sábio tenta controlar o futuro."

R. L. Ackoff (1974, p.1) 